\title{
Effects of Digital Game-Based Experiential Learning on Students' Ethical Instruction Effectiveness
}

\author{
Yue Zhao ${ }^{1}$, Tingting Ding ${ }^{1^{*}}$ \\ ${ }^{1}$ Beihua University, Jilin, CHINA
}

Received 6 February 2018 - Revised 10 April 2018 - Accepted 7 May 2017

\begin{abstract}
Along with rapid advance in cities and economic structure changes, traditional family structure and concept are changing to affect learning attitudes and behavior quality to result in crises in the operation of healthy society. "Ethical instruction" therefore has become the emphasis of global education in the $21^{\text {st }}$ century. The practice of ethical instruction in life allows students learning the virtue of behavior in life and stressing on the meanings of learning in practice and continued education. Gorgeous pictures, animations, and films presented on computers change children's learning methods to become easily accepting stimulating information, but not used to reading texts. Apparently, the establishment of digital games plays an important role in learning process. With nonequivalent pretest posttest control group design, 261 students of Beihua University are proceeded 15-week (3 hours per week for total 45 hours) experimental teaching in this study. The research results show significant effects of 1.digital game-based teaching on ethical instruction effectiveness, 2.experiential learning on ethical instruction effectiveness, and 3.digital game-based teaching integrated experiential learning on the promotion of ethical instruction effectiveness. According to the results, suggestions are proposed, expecting to guide learners solving problems in games so that students could solve problems by themselves to achieve autonomous learning. Besides, it allows students experiencing and learning in situations, establishing good ethics to change the attitudes and behaviors in similar situations in the future, and cultivating the concepts of responsibility, respect, concern, helping each other, cooperation, and bravery as well as healthy personality.
\end{abstract}

Keywords: digital game-based teaching, effectiveness, experiential learning, conventional morality

\section{INTRODUCTION}

The rapid advance of cities and the changes in economic structure have changed the structure and concept of traditional families. Two-paycheck families and single-parent families are increasing, the idea of gender equality is popular, and female educational attainment and socioeconomic status are enhanced that they start to walk out of families and engage in workplaces for living or other economic factors. When parents are working, the protection function of family is largely reduced that parents, due to being busy, might not find out children's deviated behaviors at the first time to correct the wrong behaviors and miss the primary time for cultivating children's correct concepts. Besides, with decreasing number of students, students are lack of interpersonal interaction at schools that the personality development is easily deviated to affect the learning attitudes and behavior quality; the operation of healthy society therefor appears crises. "Ethical instruction" therefore becomes primary in global education in the $21^{\text {st }}$ century. However, ethical instruction is not a formal subject, but the integration and cultivation of attitude to life, which especially requires the match of schools, families, and society. The practice of ethical instruction in life allows students learning the virtue of behavior in life and emphasizing the meanings of learning in practice and

(C) 2018 by the authors; licensee Modestum Ltd., UK. This article is an open access article distributed under the terms and conditions of the Creative Commons Attribution License (http://creativecommons.org/licenses/by/4.0/). 《173840367@qq.cm 《41311256@qq.com (*Correspondence) 


\section{Contribution of this paper to the literature}

- The cooperative and discussion learning could enhance the learning climate of the class; besides, the practice of experiential learning based on digital game-based teaching could have students be more active in the knowledge learning.

- It is suggested to collect students' feedback with learning sheets, which could help teachers understand students' comprehension; especially, students with less speech and being shyness could be analyzed personal performance and course satisfaction through feedback in order to provide assistance for special conditions or attitudes.

- Teachers integrating digital game-based teaching into instruction could make learning more diversified and courses more active and interesting as well as better enhance students' learning intention and motivation.

continued education. In this case, having students experience the importance of character education could acquire the best learning outcome.

With decreasing birth rate, parents pay lots of attention to taking care of children so that children contact computers from early ages and get used to gorgeous pictures, animations, and films presented on computers. Children therefore change the learning methods and become easily to accept stimulating information, but not used to reading texts. As a result, teachers, with traditional didactic teaching, often discover that students could not concentrate on lessons. Traditional blackboard teaching stresses on teachers' one-way delivery of subject knowledge, and students passively receive knowledge. When students lose the autonomy and decision of learning, they would feel dull learning. On the contrary, students do not appear distraction and bore in the experimental lessons. Accordingly, practice opportunities and learning autonomy in the learning courses are the keys in the promotion of students' learning motivation. Learners could enhance learning motivation and effectiveness by being induced to think of solutions and strategies for reflective problems through communication, dialogue, and discrimination and to construct new knowledge through the process. Apparently, the establishment of digital games plays a critical role in learning process. Digital games are therefore utilized in this study for students' ethical instruction and discussing students' learning outcome. It is expected to guide learners' learning through solving problems in games so that students could solve problems on their own to achieve autonomous learning. Besides, each student could directly participate in. Such active learning for training problem-solving and data organization abilities could cultivate students' exploratory and innovative spirits and allow students establishing good ethics by experiencing and learning in situations. In this case, they could change the attitudes and behaviors in similar situations in the future to cultivate the concepts of responsibility, respect, concern, helping each other, cooperation, and bravery as well as healthy personality.

\section{LITERATURE REVIEW}

\section{Digital Game-based Teaching}

Games and new technology have played an important role in human life, learning, and education (Reid-Griffin \& Slaten, 2016; Rocha et al., 2017; de Almeida Cruz \& de Azevedo Silva, 2017; Abbasi et al., 2018). Chen and Chen (2014) defined digital game-based teaching as the "software with entertainment or education developed on computers". Manek, Shenoy, Mohan, and Venugopal (2017) defined digital games as "using electronic patterns and matching program languages to present game rules on screens". Such definitions might be different, but revealed that games were presented through computers. Jude, Kajura, and Birevu (2014) regarded digital game-based teaching as virtual reality situated learning established with games, allowing learners, as "citizens" (roles in the story), participating in the virtual situation to achieve effective learning by exchanging, interacting, and cooperating with members. It could induce learners' learning motivation and achieve the objective to cultivate comprehensive abilities with situated learning. More importantly, it allowed students learning knowledge and abilities in games and more easily transferring to real life. Atenas and Havemann (2014) stated that people learn a lot of new skills and acquire knowledge and experiences in digital game-based teaching. Game-designed education aimed to induce and foster students' creativity and allowed students applying imagination, with the experiences and knowledge in the game-based learning process, to induce "fluency", "openness", "flexibility", "uniqueness", and "elaboration" in cognition as well as cultivate "adventure", "curiosity", "imagination", and "challenge" in affection (MichelaMortara et al., 2014). Lee and Hao (2015) proposed that game-based teaching should design story situations and skills according to learning goals. Subasi, Alickovic, and Kevric (2017) mentioned that games were the method to induce learning motivation, but not the learning focus, that activities suitable for the practice at various stages and proper difficulties are designed with clearly rules, attractive situations, and understanding of learners' knowledge and skills. 


\section{Experiential Learning}

Experience presents the process going through certain affairs or certain perception (Bartholomew, 2015). In other words, experiential learning is the learning process established through perceived activities in individual intrinsic world and extrinsic world, which is proceeded through thinking, perception, and physical activities (Khalid, Khalil, \& Nasreen, 2014). The content of experiential learning therefore should cover following learning meanings (Agarwal \& Mittal, 2014). (1) Experiential learning: learning from actual experiences. (2) Mobile learning: learning from observation, attempts, and implementation. (3) Reflective learning: reinforcing living abilities from a series of reflection. (4) Ability learning: stressing more on learning ability than knowledge acquisition in the entire learning process. Experiential learning started from experience, reflection, discussion \& analysis, re-experience \& analysis to the construction of internalization meaning and value. Ibáñez et al. (2014) explained experiential learning that teachers proceeded planning and discussions with students in the beginning of activities or guided students to the discussion and execution at the same time, guided students to re-think the conditions in the process after the activity, and discussing the pictures with deep impression or other ideas, and then guided the application of experience to next activity or real life. Such a run of activity and learning cycled the activity processes to generate more learning and growth. Such a process was called experiential learning circle (Sáez-López, Román-González, \& Vázquez-Cano, 2014). Experiential learning aimed to provide learners with constant acquisition of direct experiences and real-time feedback; learners acquired the opportunities to apply and test learning contents, express the understanding of activities, be aware of self, develop personal interests, and enrich life experience.

\section{Ethical Instruction Effectiveness}

Cai, Wang, and Chiang (2014) described the goal and objective of ethical instruction as to guide humans doing good and cultivating good cognitive value through education, expecting to present good performance on life events. Kuo and Chao (2014) indicated that ethical instruction enhanced the society, individual responsibility and good personality traits, and moral value with strategic guidance. Molaee and Dortaj (2015) regarded ethical instruction as teaching activities composed of all education for students, teaching the value with contribution required for life and community interests. Alickovic and Subasi (2016) pointed out ethical instruction as helping students become positive and self-directed people in real life and education processes to make efforts for future directions. Shahabadi and Uplane (2014) regarded ethical instruction as the long-term process to cultivate good personality of the youth. Good ethical instruction effectiveness should contain the ideas of comprehension, helping each other, fairness, honesty, sympathy, responsibility, and respect to oneself and others. Jin, Zhao, Chow, and Pecht (2014) covered moral education, citizenship education, and personality growth and development in ethical instruction effectiveness to facilitate individuals changing the moral regulation in education and learning in the growth process. Maeng and Lee (2015) regarded ethical instruction as value education. In addition to teaching students knowing, loving, and doing good, it would shape good behaviors as personal characters. Ethical instruction effectiveness was the process internalizing learning contents conforming to social moral standards into habits.

Referring to Chao (2016), knowledge, affection, and ability are three major elements of ethical instruction. The measurement of the effectiveness of ethics development contains following dimensions.

(1) Instinctive action: Behavior motivation is resulted from physiological impulse to satisfy individual instinct basic needs. The objectives of activities might be moral, but immoral behaviors are performed at the stage.

(2) Conventional morality: Behavioral performance following existing regulations in the society. Individual behaviors would be inspected and restrained by groups, and the violation might result in punishment or exclusion.

(3) Reflective morality: Being able to criticize existing rules and regulations in the society which are followed after individual thinking. It is the moral behavior with intrinsic wisdom, rationality, and conscience.

\section{RESEARCH HYPOTHESIS AND METHOD}

\section{Research Hypothesis}

Manek et al. (2017) indicated that digital game-based teaching was considered as the teaching method which could best induce students' learning motivation, as the positive activities in games could design learning processes as interesting as games; it was an ideal learning method to effectively promote learning outcome (Uysal \& Gunal, 2014). Nikou and Economides (2017) applied digital game-based teaching to learning situations to generate fun, induce children's learning motivation through the challenge and stimulation of digital games to acquire continuous sense of excitement, and further enhance learning outcome. Digital game-based teaching could break the ice between learning goals and teaching tactics as well as reduce teaching seriousness for children freely developing 
Table 1. Difference analysis of digital game-based teaching

\begin{tabular}{|c|c|c|c|c|}
\hline Variable & Teaching Method & Mean & $\mathbf{F}$ & $\mathbf{P}$ \\
\hline \multirow[b]{2}{*}{ instinctive action } & digital game-based teaching & 4.37 & \multirow{2}{*}{11.751} & \multirow{2}{*}{$0.000^{* *}$} \\
\hline & general teaching & 3.26 & & \\
\hline \multirow{2}{*}{ conventional morality } & digital game-based teaching & 4.15 & \multirow{2}{*}{13.426} & \multirow{2}{*}{$0.000^{\star}$} \\
\hline & general teaching & 3.02 & & \\
\hline \multirow{2}{*}{ reflective morality } & digital game-based teaching & 3.88 & \multirow{2}{*}{14.223} & \multirow{2}{*}{$0.000^{* \star}$} \\
\hline & general teaching & 2.62 & & \\
\hline
\end{tabular}

* stands for $p<0.05$ and ${ }^{* *}$ for $p<0.01$

the creative thinking in the learning process. Vanderhoven et al. (2015) stated that the function and educational meanings of games were affirmed by many experts and scholars. With the fun from digital game-based teaching, children could complete learning goals in thinking and experience to achieve the learning outcome as well as satisfy the fun of gaming and learning. It therefore was the meaningful activity (Sanjay, 2016). Accordingly, the following hypothesis is proposed in this study.

H1: Digital game-based teaching shows significant effects on ethical instruction effectiveness.

Wu and Kuo (2014) produced learning situations through media or environment for students proceeding ethical instruction with the experiences. Curriculum projects like picture books, biographic story reading, newspaper reading and classic reading aloud, dramas, aphorisms, film appreciation, games, and adventure education showed remarkable effects on ethical instruction effectiveness. $\mathrm{Ng}$ (2016) regarded ethical instruction as the attitude to life that learning could be preceded through experience anytime anywhere; pupils therefore could present behavioral and conceptual learning which required the overall climate created by schools, families, and the entire society. Valerie (2015) mentioned that matching ethical instruction with experiential learning situation design could achieve teaching effectiveness with less effort. Romrell, Kidder, and Wood (2014) indicated that teachers could integrate existing subjects in the practice and design of ethical instruction and proceed ethical instruction with experiential learning as the body to help students cultivate core competency, induce learning interests and potential, and utilize life knowledge for the optimal learning outcome (Woo, 2014). For this reason, the following hypotheses are proposed in this study.

H2: Experiential learning shows notable effects on ethical instruction effectiveness.

H3: Digital game-based teaching integrated experiential learning reveal significant effects on the promotion of ethical instruction effectiveness.

\section{Research Object and Research Design}

To effectively achieve research objectives and test research hypotheses, nonequivalent pretest posttest control group design is applied to the experimental research. Total 261 students of Beihua University are proceeded digital game-based teaching integrated experiential learning $2 / 2$ experiment, which is grouped experiential learning (experiential learning, general traditional teaching) $X$ digital game-based teaching (digital game-based teaching, general traditional teaching) for 15 -week (3 hours per week for total 45 hours) experimental teaching.

\section{Analysis Method}

Analysis of Variance is utilized in this study for discussing the effect of digital game-based teaching on students' ethical instruction effectiveness and the effect of experiential learning on students' ethical instruction effectiveness as well as understanding the effect of digital game-based teaching integrated experiential learning on students' ethical instruction effectiveness.

\section{RESULT AND ANALYSIS}

\section{Difference Analysis of Digital Game-based Teaching in Ethical Instruction Effectiveness}

With Analysis of Variance, the difference of digital game-based teaching in instinctive action, conventional morality, and reflective morality is discussed. From Table 1, digital game-based teaching and general traditional teaching show remarkable differences in instinctive action, where digital game-based teaching appears higher instinctive action than general traditional teaching. Furthermore, digital game-based teaching and general traditional teaching reveal notable differences in conventional morality, where digital game-based teaching appears higher conventional morality than general traditional teaching. Finally, digital game-based teaching and general traditional teaching reveal significant differences in reflective morality, where digital game-based teaching shows higher reflective morality than general traditional teaching that $\mathrm{H} 1$ is supported. 
Table 2. Difference analysis of experiential learning

\begin{tabular}{|c|c|c|c|c|}
\hline Variable & Teaching Method & Mean & $\mathbf{F}$ & $\mathbf{P}$ \\
\hline \multirow{2}{*}{ instinctive action } & experiential learning & 4.42 & \multirow{2}{*}{14.184} & \multirow{2}{*}{$0.000^{\star \star}$} \\
\hline & general teaching & 3.31 & & \\
\hline \multirow{2}{*}{ conventional morality } & experiential learning & 4.05 & \multirow{2}{*}{12.631} & \multirow{2}{*}{$0.000^{* *}$} \\
\hline & general teaching & 3.22 & & \\
\hline \multirow{2}{*}{ reflective morality } & experiential learning & 4.41 & \multirow{2}{*}{21.586} & \multirow{2}{*}{$0.000^{* *}$} \\
\hline & general teaching & 2.57 & & \\
\hline
\end{tabular}

Table 3. Difference analysis of digital game-based teaching in ethical instruction effectiveness

\begin{tabular}{|c|c|c|c|c|c|c|c|c|c|}
\hline \multirow[t]{2}{*}{ Variable } & \multicolumn{3}{|c|}{ Instinctive Action } & \multicolumn{3}{|c|}{ Conventional Morality } & \multicolumn{3}{|c|}{ Reflective Morality } \\
\hline & $\mathbf{F}$ & $\mathbf{P}$ & Scheffe & $\mathbf{F}$ & $\mathbf{P}$ & Scheffe & $\mathbf{F}$ & $\mathbf{P}$ & Scheffe \\
\hline $\begin{array}{l}\text { digital game-based } \\
\text { teaching }\end{array}$ & 11.751 & $0.000^{* *}$ & $\begin{array}{c}\text { gamed-based }> \\
\text { general }\end{array}$ & 13.426 & $0.000^{* *}$ & $\begin{array}{c}\text { gamed-based } \\
>\text { general }\end{array}$ & 14.223 & $0.000^{\star *}$ & $\begin{array}{c}\text { gamed-based }> \\
\text { general }\end{array}$ \\
\hline experiential learning & 14.184 & $0.000^{\star *}$ & $\begin{array}{c}\text { Experiential > } \\
\text { general }\end{array}$ & 12.631 & $0.000^{* *}$ & $\begin{array}{c}\text { Experiential > } \\
\text { general }\end{array}$ & 21.586 & $0.000^{\star *}$ & $\begin{array}{c}\text { Experiential > } \\
\text { general }\end{array}$ \\
\hline $\begin{array}{l}\text { digital game-based } \\
\text { teaching*experiential } \\
\text { learning }\end{array}$ & 26.772 & $0.000^{\star *}$ & $11>12>21>22$ & 33.216 & $0.000^{* *}$ & $11>21>12>22$ & 37.625 & $0.000^{\star *}$ & $11>21>12>22$ \\
\hline
\end{tabular}

\section{Difference Analysis of Experiential Learning in Ethical Instruction Effectiveness}

Analysis of Variance is utilized for discussing the difference of experiential learning in instinctive action, conventional morality, and reflective morality. From Table 2, experiential learning and general traditional teaching shows notable differences in instinctive action, where experiential learning reveals higher instinctive action than general traditional teaching. Moreover, experiential learning and general traditional teaching appear significant differences in conventional morality, where experiential learning shows higher conventional morality than general traditional teaching. Finally, experiential learning and general traditional teaching reveal remarkable differences in reflective morality, where experiential learning appears higher reflective morality than general traditional teaching that $\mathrm{H} 2$ is supported.

\section{Effects of Experiential Learning Integrated Digital Game-based Teaching}

Analysis of Variance is used for discussing the difference of digital game-based teaching integrated experiential learning in students' ethical instruction effectiveness, and two-way Analysis of Variance is applied to discuss the interaction of digital game-based teaching and experiential learning to verify the enhancement of experiential learning. From Table 3, digital game-based teaching integrated experiential learning presents the highest instinctive action, conventional morality, and reflective morality that $\mathrm{H} 3$ is supported.

\section{DISCUSSION}

Teachers have to maintain students' classroom orders and arrange the review plans that the attitudes towards students are comparatively serious and strict. However, when proceeding experiential learning of ethics education with digital game-based teaching, teachers are no longer the authority in classrooms, but would shorten the teacherstudent gap by making jokes with students to enhance the course climate and fun. The mutual support and encouragement among teams are enhanced to increase the trust between teachers and students. Students would actively share the happiness and frustration in life so that teachers could better understand students, make effective communications, and arrange courses to avoid deviation behaviors. After completing experiential learning of ethics education with digital game-based teaching, it is discovered that students improve the attitudes and performance on extracurricular or other off-campus teaching activities, such as praising/encouraging others, reducing the situations of not handing in homework, and being active and positive to the duties. Such behavior changes are not perceived in short time, but require long period of ethics education for the surprising growth of students. Teachers and parents should give supports and encouragement to students' positive changes in ethnic behaviors (e.g. being autonomous and polite to classmates and teachers) to further promote students' ethnic behaviors. 


\section{CONCLUSION}

The research results reveal that proceeding experiential learning of ethical instruction with digital game-based teaching could improve students' behaviors and remind each other when other classmates make mistakes. Especially, students become considerate and helpful and could active concern about other students and provide assistance, the class coherence is enhanced, learning climate gets better, and the conditions of peers attacking each other with languages are improved. Proceeding experiential learning with digital game-based teaching could present positive effects on participants' ethical instruction. In addition to preset curriculum projects, accident events in lessons could be the material of opportunity education to reinforce students' concept of ethical instruction and behavioral learning. With digital game-based teaching teams, team members could exchange opinions and share experience to help promote course quality and achieve co-growth of the team. Besides, reducing the changes of course field and uncertainties to the lowest in the course practice could enhance participants' attention.

\section{SUGGESTION}

According to the research conclusion, the following suggestions are proposed in this study.

1. Regarding ethical instruction based on digital game-based teaching for experiential learning, it is discovered that students could better integrate the learned knowledge after the experience. For this reason, teachers, when instructing problem solving, should encourage students to find out solutions and discuss with peers as well as proceed teaching with accessible real cases when guiding the problem solving. The cooperative and discussion learning could enhance the learning climate of the class; besides, the practice of experiential learning based on digital game-based teaching could have students be more active in the knowledge learning.

2. In ethical instruction, situations or important concepts are chosen for deepening students' understanding of ethical instruction. It is suggested to collect students' feedback with learning sheets, which could help teachers understand students' comprehension; especially, students with less speech and being shyness could be analyzed personal performance and course satisfaction through feedback in order to provide assistance for special conditions or attitudes.

3. Students could learn through digital game-based teaching without pressure and under relaxing and interesting environment so that students are glad to participate in and enhance the learning motivation and maintain the attention. For this reason, teachers integrating digital game-based teaching into instruction could make learning more diversified and courses more active and interesting as well as better enhance students' learning intention and motivation. Digital game-based teaching could effectively induce learning motivation; however, it needs to constantly expand the materials and digital game functions to keep freshness for the continuous use of students. In this case, digital game contents should be timely updated, according to the needs of courses, to attract students and effectively induce the learning motivation.

\section{ACKNOWLEDGEMENT}

This work was supported in part by "Research on the dilemma and countermeasures of news ethics in the context of whole media communication", Social Science Fund Project of Jilin Province (No. 2016B257).

\section{REFERENCES}

Abbasi, S., Moeini, M., Shahriari, M., Ebrahimi, M., Khoozani, E. K. (2018). Designing and manufacturing of educational multimedia software for preventing coronary artery disease and its effects on modifying the risk factors in patients with coronary artery disease. Electronic Journal of General Medicine, 15(3), em22. https:// doi.org/10.29333/ejgm/85942

Agarwal, B., \& Mittal, N. (2014). Text classification using machine learning methods-a survey. In Proceedings of the Second International Conference on Soft Computing for Problem Solving (SocProS 2012), December 28-30, 2012 (pp. 701-709). Springer, New Delhi. https://doi.org/10.1007/978-81-322-1602-5_75

Alickovic, E., \& Subasi, A. (2016). Medical decision support system for diagnosis of heart arrhythmia using DWT and random forests classifier. Journal of medical systems, 40(4), 1. https:/ / doi.org/10.1007/s10916-016-04678

Atenas, J., \& Havemann, L. (2014). Questions of quality in repositories of open educational resources: a literature review. Research in Learning Technology, 22(1), 20889. https:/ / doi.org/10.3402/rlt.v22.20889

Bartholomew, S. (2015). My journey with self-directed learning. Techniques: Connecting Education E Careers, 90(2), 46-50. 
Cai, S., Wang, X., \& Chiang, F. K. (2014). A case study of Augmented Reality simulation system application in a chemistry course. Computers in Human Behavior, 37, 31-40. https:/ / doi.org/10.1016/j.chb.2014.04.018

Chao, P. Y. (2016). Exploring students' computational practice, design and performance of problem-solving through a visual programming environment. Computers $\mathcal{E}$ Education, 95, 202-215. https:/ / doi.org/10.1016/j.compedu.2016.01.010

Chen, C. M., \& Chen, F. Y. (2014). Enhancing digital reading performance with a collaborative reading annotation system. Computer and Education, 77, 67-81. https:/ / doi.org/10.1016/j.compedu.2014.04.010

de Almeida Cruz, J. J., \& de Azevedo Silva, K. K. (2017). Relational Algebra Teaching Support Tool. Journal of Information Systems Engineering \& Management, 2(2), 8. https:/ / doi.org/10.20897/jisem.201708

Jin, X., Zhao, M., Chow, T. W., \& Pecht, M. (2014). Motor bearing fault diagnosis using trace ratio linear discriminant analysis. IEEE Transactions on Industrial Electronics, 61(5), 2441-2451. https:/ / doi.org/10.1109/TIE.2013.2273471

Jude, L. T., Kajura, M. A., \& Birevu, M. P. (2014). Adoption of the SAMR Model to Assess ICT Pedagogical Adoption: A Case of Makerere University. International Journal of e-Education, e-Business, e-Management and e-Learning, 4(2), 106-115. https:/ / doi.org/10.7763/IJEEEE.2014.V4.312

Khalid, S., Khalil, T., \& Nasreen, S. (2014). A survey of feature selection and feature extraction techniques in machine learning. In Science and Information Conference (SAI), 2014 (pp. 372-378). IEEE. https://doi.org/10.1109/SAI.2014.6918213

Kuo, C. L., \& Chao, C. Y. (2014). Exploring the relationship among patterns, information technology, and performance for SME-based service innovation. International Journal of Electronic Business Management, 12(2), 101-110.

Lee, L. C., \& Hao, K. C. (2015). Designing and Evaluating Digital Game-Based Learning with the ARCS Motivation Model, Humor, and Animation. International Journal of Technology and Human Interaction, 11(2), 80-95. https:/ / doi.org/10.4018/ijthi.2015040105

Maeng, U., \& Lee, S. M. (2015). EFL teachers' behavior of using motivational strategies: The case of teaching in the Korean context. Teaching and Teacher Education, 46, 25-36. https:/ / doi.org/10.1016/j.tate.2014.10.010

Manek, A. S., Shenoy, P. D., Mohan, M. C., \& Venugopal, K. R. (2017). Aspect term extraction for sentiment analysis in large movie reviews using Gini Index feature selection method and SVM classifier. World wide web, 20(2), 135-154. https:// doi.org/10.1007/s11280-015-0381-x

MichelaMortara, M., Catalanoa, C. E., Bellotti, F., Fiucci, G., Houry-Panchetti, M., \& Panagiotis, P. (2014). Learning cultural heritage by serious games. Journal of Cultural Heritage, 15(3), 318-325. https://doi.org/10.1016/j.culher.2013.04.004

Molaee, Z., \& Dortaj, F. (2015). Improving L2 Learning: An ARCS Instructional-motivational Approach. Procedia Social and Behavioral Sciences, 171, 1214-1222. https:/ / doi.org/10.1016/j.sbspro.2015.01.234

$\mathrm{Ng}$, E. M. (2016). Fostering pre-service teachers' self-regulated learning through self-and peer assessment of wiki projects. Computers E Education, 98, 180-191. https:/ / doi.org/10.1016/j.compedu.2016.03.015

Nikou, S. A., \& Economides, A. A. (2017). Mobile-based assessment: Investigating the factors that influence behavioral intention to use. Computers $\mathcal{E}$ Education, 109, 56-73. https:/ / doi.org/10.1016/j.compedu.2017.02.005

Reid-Griffin, A., \& Slaten, K. M. (2016). Wikis: Developing pre-service teachers' leadership skills and knowledge of content standards. European Journal of STEM Education, 1(1), 3-7. https:/ / doi.org/10.20897/lectito.201601

Rocha, T., Martins, J., Branco, F., \& Gonçalves, R. (2017). Evaluating Youtube Platform Usability by People with Intellectual Disabilities (A User Experience Case Study Performed in a Six-Month Period). Journal of Information Systems Engineering \& Management, 2(1), 5. https:/ / doi.org/10.20897/jisem.201705

Romrell, D., Kidder, L. C., \& Wood, E. (2014). The SAMR Model as a Framework for Evaluating m-Learning. Journal of Asynchronous Learning Networks, 18(2).

Sáez-López, J. M., Román-González, M., \& Vázquez-Cano, E. (2016). Visual programming languages integrated across the curriculum in elementary school: A two year case study using "Scratch" in five schools. Computers E Education, 97, 129-141. https:/ / doi.org/10.1016/j.compedu.2016.03.003

Sanjay, G. (2016). A Comparative Study on Face Recognition using Subspace Analysis. In International Conference on Computer Science and Technology Allies in Research-March (p. 82).

Shahabadi, M. M., \& Uplane, M. (2014). Learning Styles and Academic Performance of Synchronous E-Learning Students. Asian Journal of Research in Social Sciences and Humanities, 4(5), 148-161 
Subasi, A., Alickovic, E., \& Kevric, J. (2017). Diagnosis of Chronic Kidney Disease by Using Random Forest. In CMBEBIH 2017 (pp. 589-594). Springer, Singapore. https:/ / doi.org/10.1007/978-981-10-4166-2_89

Uysal, A. K., \& Gunal, S. (2014). The impact of preprocessing on text classification. Information Processing $\mathcal{E}$ Management, 50(1), 104-112. https://doi.org/10.1016/j.ipm.2013.08.006

Valerie, C. B. (2015). Self-Directed Learning and Technology. Education Digest, 80(6), 42-44.

Vanderhoven, E., Raes, A., Montrieux, H., Rotsaert, T., \& Schellens, T. (2015). What if pupils can assess their peers anonymously? A quasi-experimental study. Computers $\mathcal{E}$ Education, 81, 123-132. https:/ / doi.org/10.1016/j.compedu.2014.10.001

Woo, J. C. (2014). Digital Game-Based Learning Supports Student Motivation, Cognitive Success, and Performance Outcomes. Educational Technology \& Society, 17(3), 291-307.

Wu, C. H., \& Kuo, C. L. (2014). Investigating the cross effects of smart devices, collaborative learning, and instructional designs on high school students' learning outcome. In the Proceedings of the 2014 International Conference on e-Commerce, e-Administration, e-Society, e-Education, and e-Technology fall session (e-CASE $\mathcal{E} e$ Tech 2014 fall session).

\section{http://www.ejmste.com}

